\title{
The Recurrent Laryngeal Cardiac Nerve in Fetuses
}

\author{
El Nervio Laríngeo Recurrente Cardiaco en Fetos
}

\author{
B. Z. De Gama*; L. Lazarus* \& K. S. Satyapal*
}

\begin{abstract}
DE GAMA, B. Z.; LAZARUS, L. \& SATYAPAL, K. S. The recurrent laryngeal cardiac nerve in fetuses. Int. J. Morphol., 32(2):415$419,2014$.

SUMMARY: The recurrent laryngeal nerve has been reported to supply cardiac branches to the cardiac plexus. A review of anatomical literature on the existing term used to describe these branches revealed that varying interpretations and descriptions exist among various authors. Therefore, this study aimed to investigate the origin and incidence of branches from the recurrent laryngeal nerves to the cardiac plexus and their connections with sympathetic cardiac nerves. The sample comprised 40 cadaveric fetuses $(\mathrm{n}=80)$ (gestational ages: 16-30 weeks). The recurrent laryngeal cardiac nerve was described as the cardiac branch that originated directly from the recurrent laryngeal nerve and reached the superficial or deep parts of the cardiac plexus. This study found the recurrent laryngeal cardiac nerve in $76 \%$ of the cases contributing direct and indirect branches in $75 \%$ and $25 \%$ of the cases, respectively. This study recorded only two (2\%) of these branches contributing to the superficial cardiac plexus while the rest (74\%) of these branches contributed to the deep cardiac plexuses. The remaining $24 \%$ had no contributions from the recurrent laryngeal nerve to either the superficial or deep part of the cardiac plexus. The most common point of origin for the recurrent laryngeal cardiac nerve was at the lower distal part in 59\% of the specimens. In the remaining $41 \%$ of branches, this nerve originated from the point of curvature, upper proximal part and both the point of curvature and lower distal part in $26 \%, 10 \%$ and $5 \%$ of the specimens.
\end{abstract}

KEY WORDS: Recurrent laryngeal cardiac nerve; Vagus nerve; Cardiac plexus.

\section{INTRODUCTION}

The recurrent laryngeal nerve (RLN) contributes cardiac branches to the superficial (SCP) (Mitchell, 1953) and deep (DCP) (Standring et al., 2008) cardiac plexuses after it arises from the vagus nerve curves around the subclavian artery on the right and the aortic arch on the left (Standring et al.). A review of anatomical literature on the existing nomenclature used to describe these branches revealed that varying interpretations and descriptions exist according to various authors (Mitchell; Mizeres, 1972; Kawashima, 2005; Mauro et al., 2009). Previous studies adopted terms such as "inferior vagal cardiac branches" (Mitchell), "inferior cervical" (Kuntz, 1953), "recurrent cardiopulmonary nerves" (Janes et al., 1986), "cervicothoracic and left thoracic cardiac nerves" (Mizeres), "recurrent cardiac branch" (Randall \& Armour, 1977), "superior, inferior and thoracic branches" (Kawashima) and "inferior cardiac nerves" (Mauro et al.) to refer to cardiac branches originating from the RLN without specifying the exact location of the origin. Kawashima utilized the term "superior, inferior and thoracic cardiac branches" to denote cardiac branches which originated from the upper (proximal), recurrent laryngeal nerve and the lower (distal) parts of the recurrent laryngeal nerve, respectively. Current anatomical literature uses the term "additional branches" (Standring $e t$ al.) to describe these contributions given off from the trunk of the right vagus nerve and both recurrent laryngeal nerves to the deep cardiac plexus. It must be noted that some of these terms reflect different points of origin of these cardiac branches from the recurrent laryngeal nerve.

According to the Nomina Terminologica (FCAT, 1998) only tracheal, esophageal and pharyngeal branches are recorded as branches of the recurrent laryngeal nerve. Currently, the authors have noted that there is no singular anatomical term that describes cardiac branches which originate from the recurrent laryngeal nerve to either the superficial or deep components of the cardiac plexus.

With regards to connections between the cardiac branches from the RLN and the sympathetic cardiac nerves, the anatomical literature reports that branches from RLN communicate with the superior and middle cervical cardiac

* Clinical Anatomy School of Laboratory Medicine and Medical Sciences, College of Health Sciences University of KwaZulu-Natal, Durban, South Africa. 
nerves on the right side only. Mizeres stated that the cervicothoracic cardiac nerves of vagus (from RLN) communicated with cervicothoracic cardiac branches of the sympathetic chain. Kalsey et al., (2000) stated that the middle cervical cardiac nerve communicated with the RLN in two cases only. Mauro et al. described the inferior cervical cardiac nerves converging to the RLN.

Anatomically, the recurrent laryngeal nerve carries sensory and autonomic fibers to the cardiac region. Therefore, an accurate knowledge of the descriptions and origins of cardiac branches from the recurrent laryngeal nerve will also enhance the understanding of these contributions to the cardiac plexus.

This study aimed to document the origin and incidence of cardiac branches from the recurrent laryngeal nerves to the cardiac plexus and the connections that exist between these cardiac branches and the sympathetic cardiac nerves.

\section{MATERIAL AND METHOD}

The study comprised of forty cadaveric fetuses (gestational ages (GA): 16-30 weeks), which were obtained from the Discipline of Clinical Anatomy at the University of KwaZulu-Natal (Westville campus), South Africa. Fetal necks and trunks with signs of trauma were excluded from this study. The research was conducted in accordance with the National Health Act No. 61 of 2003. Ethical clearance was obtained from the Biomedical Research and Ethics Committee of the University of KwaZulu-Natal (Ethical clearance number: BF 152/07).

A Stemi-DV4 stereomicroscope (Carl Zeiss, Germany) was used in the micro-dissection process. The skin, muscles, bones and lungs were removed for exposure of the nerves. The fascia and parietal pleura of the lungs were carefully removed in order to expose the vagus and recurrent laryngeal nerves. The contributions from the recurrent laryngeal nerve were traced from their origin to their destination on the respective parts of the cardiac plexus and were captured with a Canon Digital Camera.

\section{RESULTS}

In this study, the recurrent laryngeal cardiac nerve (RLCN) was described as the cardiac branch that originated directly from the RLN and reached the superficial or deep parts of the cardiac plexus.
Incidence. In this study the RLCN is described as the cardiac branch that originated directly from the RLN reaching the superficial or deep parts of the cardiac plexus. This study found the RLCN in $61 / 80(76 \%)$ of the specimens contributing direct and indirect branches in 46/61 (75\%) and $15 / 61(25 \%)$ of cases, respectively (Table I). The direct branches were single, double and triple in $29 / 61(48 \%), 16 /$ $61(26 \%)$ and $1 / 61(2 \%)$ of specimens, respectively. The indirect branches displayed a singular and duplicate pattern of branching in 14/61 (25\%) and 1/61 (2\%) of the specimens, respectively. Furthermore, the RLCN contributed branches to the SCP in 2/61 (3\%) and to the DCP in 59/61 (97\%) of the specimens (Figs. 1 and 2). The RLCN was absent in the remaining 19/80 (24\%) of the specimens and hence had no contributions to any part of the cardiac plexus.

\begin{tabular}{ccccc}
\multicolumn{6}{l}{ Table I. Direct and indirect RLCN. } \\
\hline Cohort & GA (wks) & Direct & Indire ct & Total \\
\hline $\mathbf{1}$ & $16-20$ & 24 & 5 & 29 \\
$\mathbf{2}$ & $21-25$ & 20 & 3 & 23 \\
$\mathbf{3}$ & $26-30$ & 2 & 1 & 3 \\
\hline
\end{tabular}

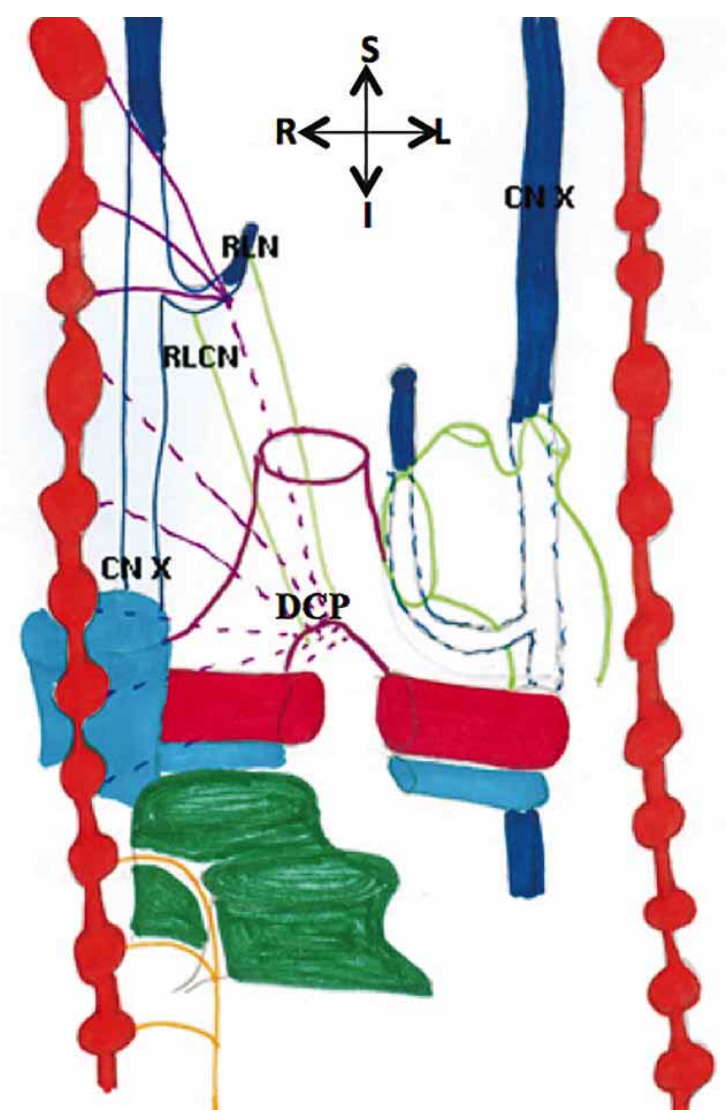

Fig. 1. Diagrammatic representation of the origin of the RLCN from the RLN. CN X= Vagus nerve, DCP= Deep cardiac plexus, RLCN= Recurrent laryngeal cardiac nerve, $\mathrm{RLN}=$ Recurrent laryngeal cardiac nerve. $\mathrm{S}=$ Superior, $\mathrm{L}=\mathrm{Left}, \mathrm{I}=\mathrm{Inferior}, \mathrm{R}=$ Right. 


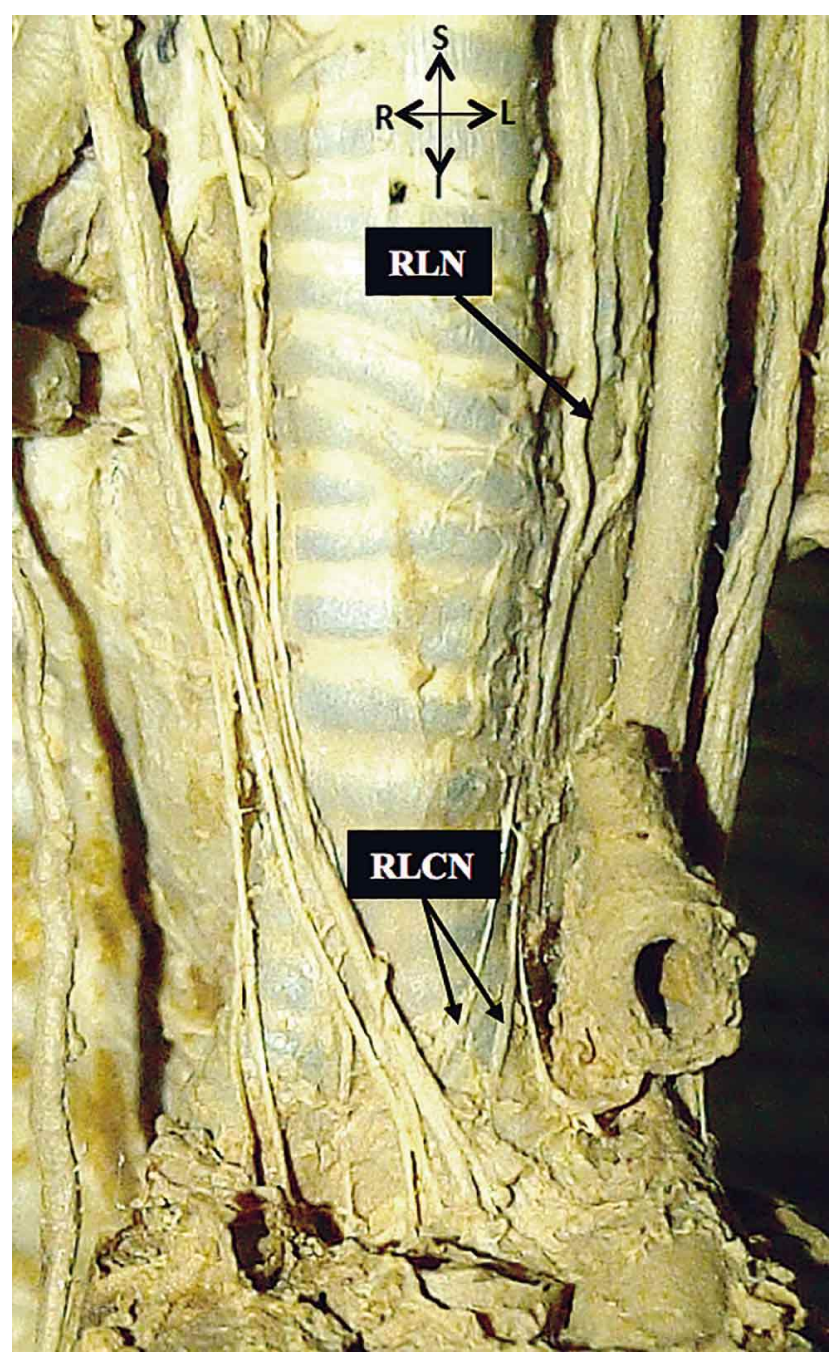

Fig. 2. An anterior view of the RLCN originating from lower distal part of RLN (Left side). CN X= Vagus nerve, RLCN= Recurrent laryngeal cardiac nerve, RLN= Recurrent laryngeal cardiac nerve. $\mathrm{S}=$ Superior, $\mathrm{L}=\mathrm{Left}, \mathrm{I}=$ Inferior, $\mathrm{R}=$ Right.

Point of origin. The RLCN originated from the: (i) lower distal part of the RLN (Fig. 2) in 36/61 (59\%) (ii) upper proximal part of the RLN in 3/61 (5\%) (iii) Point of curvature of the RLN in 16/61 (26\%) (Fig. 3) (iv) both the lower distal

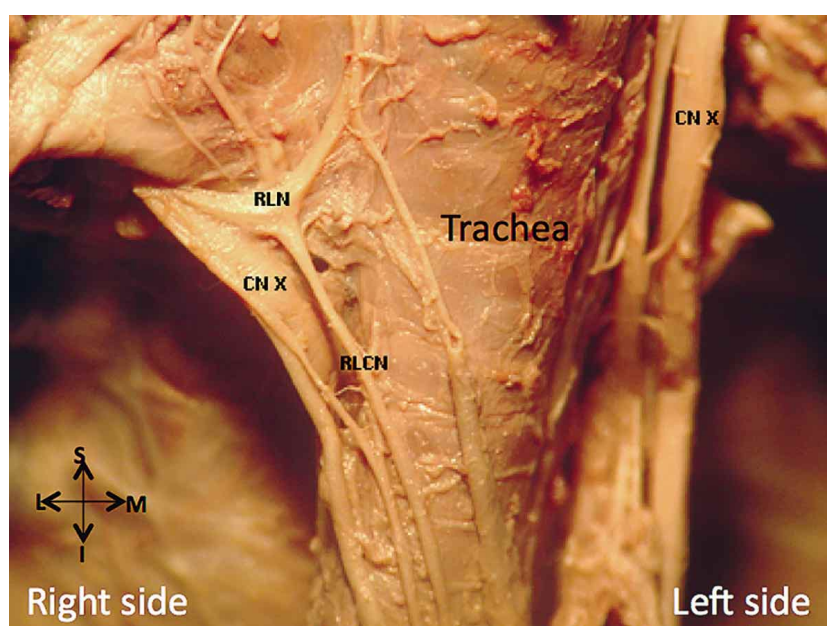

Fig. 3. An anterolateral view of the thorax demonstrating the curving of RLN with RLCN branch to DCP (Right side). CN X= Vagus nerve, RLCN= Recurrent laryngeal cardiac nerve, RLN= Recurrent laryngeal cardiac nerve. $\mathrm{S}=$ Superior, $\mathrm{M}=$ Medial, $\mathrm{I}=$ Inferior, $\mathrm{L}=$ lateral.

part and curvature of the RLN (Both1) in 4/61 (7\%) (v) both the upper proximal and lower distal part of the RLN (Both2) in $2 / 61(3 \%)$ of the specimens, respectively. The origins (iii) and (iv) were frequent found in fetuses of GA 16 to 20 weeks while origins and (i) and (ii) were frequent in GA of 21 to 25 weeks. Origin (v) was found in fetuses of GA 16 to 20 and 21 to 25 weeks. The varying points of origin are reflected in Table III.

Connections with sympathetic cardiac nerves. The RLCN communicated with the sympathetic cardiac nerves in 25/ $61(41 \%)$ of the cases. The most frequent communication was with the middle cervical cardiac nerve (MCCN) in 10/ $25(40 \%)$ of the cases. Furthermore, the RLCN communicated with the superior cervical cardiac nerve (SCCN), inferior cervical cardiac nerve (ICCN) and cervicothoracic cardiac nerve (CTCN) in $6 / 25(24 \%), 1 / 25$ (4\%), 3/25 (12\%) of the cases. The RLCN also communicated with both SCCN and MCCN joint nerves in $5 / 25(20 \%)$ of the cases. This occurred bilaterally in fetuses aged 21 to 25 weeks.

Table II. Incidence of Points of origin of the RLCN.

\begin{tabular}{ccccccc}
\hline Cohort & GA (wks) & Upper proximal & Lower distal & Curve & Both $_{\mathbf{1}}$ & Both $_{\mathbf{2}}$ \\
\hline $\mathbf{1}$ & $16-20$ & 2 & 17 & 11 & 3 & 1 \\
$\mathbf{2}$ & $21-25$ & 1 & 15 & 5 & 1 & 1 \\
$\mathbf{3}$ & $26-30$ & 0 & 4 & 0 & 0 & 0 \\
\hline
\end{tabular}

Key: Both1- Lower distal and curve; Both2- Upper proximal and point of curvature; GA- Gestational age

Table III. Percentage contributions from RLN to the deep cardiac plexus.

\begin{tabular}{ccccc}
\hline $\begin{array}{c}\text { Origin of contribution } \\
\text { RLN }\end{array}$ & Contribution & Incidence $(\%)$ & Right $(\mathrm{n}=40)$ & Left $(\mathrm{n}=40)$ \\
\hline & RLCN & 76 & 33 & 28 \\
\hline
\end{tabular}




\section{DISCUSSION}

Parasympathetic contributions from the recurrent laryngeal nerve to the cardiac plexus are an anatomical misperception. The variability that exists in the literature on the contributions from the RLN to the cardiac plexus (Mizeres; Randall \& Armour, 1977, Janes et al.; Kadowaki \& Lewett, 1986; Kawashima; Mauro et al.) together with descriptions of the sympathetic contributions (Kuntz \& Morehouse, 1930; Saccomanno, 1943; Groen et al., 1987, Kalsey et al.; Pather et al., 2003, Kawashima) account for the confusion in the description and interpretation of the parasympathetic supply to the cardiac plexus.

The anatomical literature reports that the RLN gives off cardiac branches to the deep part of the cardiac plexus via "additional branches" (Standring et al.). The RLCN in this study is described as the cardiac branch that originated directly from the RLN and reached the superficial or deep parts of the cardiac plexus. This study reports an incidence of $76 \%$ for the RLCN which compares significantly with the findings of Kawashima on the classification of cardiac branches from the RLN who reported an incidence of $100 \%$. However, in the study conducted by Randall \& Armour no incidence of the RLCN was published. The direct branches consisted of single, double and triple branches while the indirect branches had singular and duplicate pattern only. This differed widely from the findings of Kuntz who described a singular branch from RLN and Kawashima who reported these branches as varying from one to five. The SCP received $3 \%$ of the branches while the DCP received $97 \%$ of the RLCN branches; this differs from anatomical literature (Standring et al.) and concurs with Mitchell's contribution of inferior vagal cardiac branches to SCP and DCP. These findings of this study validate that parasympathetic cardiac branches "are variable in their size, number and distribution from the vagi both in the neck and thorax" (Mitchell).

This study also concurs with points of origin of RLN reflected by Kawashima, as they were all identified in the specimens although they varied in number. The incidence of branches originating from the different parts of RLN (i.e. upper proximal and lower distal) of 5\% and 59\%, respectively differed widely from Kawashima who recorded incidences of $100 \%$ and $77.8 \%$. This could be due to the varying nomenclature used in classification of the cardiac branches from RLN. This study further identified points of origin from the RLN from both the lower distal and point of curvature in one specimen, and from both upper proximal and point of curvature in one specimen. These points of origin were not identified in the study by Kawashima.
With respect to connections that exist between the RLCN and sympathetic cardiac nerves, this study recorded this occurrence in $41 \%$ of the specimens. The most frequent connection occurred between RLCN and MCCN in $40 \%$ of the cases, this differed widely from Kalsey et al., who stated this occurrence in two cases only. The SCCN, ICCN and CTCN had connections with RLCN in $24 \%, 4 \%$ and $12 \%$, respectively. These findings agree with Kuntz in that "as vagal fibers approach the cardiac plexus they mingle with the cardiac sympathetic fibers".

Furthermore, the findings of this study appear to concur with the term "recurrent laryngeal cardiac nerve", as proposed by Randall \& Armour in 1977, to describe cardiac branches that originate from the RLN irrespective of their point of origin viz. either the curvature, the lower distal part of nerve or both curvature and lower distal part of nerve.

\section{CONCLUSION}

The findings of this study appear to be unique as it reports on the incidence, point of origin and the number of connections with the sympathetic cardiac branches of the contributions of the RLN to the superficial and deep cardiac plexuses. Additionally, it is recommended that the correct nomenclature to describe these branches from the RLN to the cardiac plexus be adopted universally to avoid perpetuating confusion. Therefore, the term "recurrent laryngeal cardiac nerve" is proposed for use to describe the contributions of the RLN to the cardiac plexuses.

\section{ACKNOWLEDGEMENTS}

The authors would like to acknowledge the contribution from the late Professor Prawesh Partab in this work.

DE GAMA, B. Z.; LAZARUS, L. \& SATYAPAL, K. S. El nervio recurrente laríngeo cardiaco en fetos. Int. J. Morphol., 32(2):415-419, 2014.

RESUMEN: El nervio laríngeo recurrente se ha reportado que suministra las ramas cardiacas para el plexo cardíaco. Una revisión de la literatura anatómica indica que se ha descrito estas ramas y que existen diferentes interpretaciones y descripciones de los distintos autores. En consecuencia este estudio tuvo como ob- 
jetivo investigar el origen, además de la incidencia de las ramas de los nervios laríngeos recurrentes al plexo cardíaco y sus conexiones con los nervios cardiacos simpáticos. La muestra incluyó 40 fetos cadavéricos ( $\mathrm{n}=80)$ (edades gestacionales: 16-30 semanas). El nervio laríngeo recurrente cardiaco fue descrito como la rama cardíaca que originó directamente del nervio laríngeo recurrente, que llega a las partes superficiales o profundas del plexo cardíaco. En este estudio observamos que el nervio laríngeo recurrente cardiaco en el $76 \%$ de los casos contribuye a las ramas directas e indirectas, en el $75 \%$ y el $25 \%$ de los casos, respectivamente. Este estudio registró solamente dos $(2 \%)$ de estas ramas que contribuyen a la plexo cardíaco superficial, mientras que el resto (74\%) de estas ramas contribuyó a los plexos cardíacos profundos. El $24 \%$ restante no tenía contribuciones del nervio laríngeo recurrente ya sea la parte superficial o profunda del plexo cardíaco. El punto de origen más común del nervio laríngeo recurrente cardiaco se observó en la parte distal inferior en un 59\% de las muestras. En el $41 \%$ restante de las ramas este nervio se originó desde el punto de curvatura, la parte proximal superior y tanto en el punto de curvatura inferior como la parte distal en $26 \%, 10 \%$ y $5 \%$ de los especímenes.

PALABRAS CLAVE: Nervio laríngeo recurrente cardiac; Nervio vago; Plexo cardiaco.

\section{REFERENCES}

Federative Committee on Anatomical Terminology (FCAT). Terminología Anatómica: International Anatomical Terminology. Stuttgart, Georg Thieme Verlag, 1998.

Groen, G. J.; Baljet, B.; Boekelaar, A. B. \& Drukker, J. Branches of the thoracic sympathetic trunk in the human fetus. Anat. Embryol. (Berl.), 176(4):401-11, 1987.

Janes, R. D; Brandys, J. C.; Hopkins, D. A.; Johnstone, D. E.; Murphy, D. A. \& Armour, J. A. Anatomy of human extrinsic cardiac nerves and ganglia. Am. J. Cardiol., 57(4):299-309, 1986.

Kadowaki, M. H. \& Levett, J. M. Sympathectomy in the treatment of Anginas and Arrythmias. Ann. Thorac. Surg., 41(5):572-8, 1986.

Kalsey, G.; Mukherjee, R. N. \& Patnaik, V. V. G. A comparative study of cervical sympathetic chain. J. Anat. Soc. India., 49(1):26-30, 2000.

Kawashima, T. The autonomic nervous system of the human heart with special reference to its origin, course, and peripheral distribution. Anat. Embryol. (Berl.), 209(6):425-38, 2005.

Kuntz, A. The autonomic nervous system. 4th ed. Philadelphia, Lea \& Febiger, 1953.

Kuntz, A. \& Morehouse, A. Thoracic sympathetic cardiac nerves in man: their relation to cervical sympathetic ganglionectomy. Arch. Surg.,20(4):607-13, 1930.

Mauro, M. P. S.; Patronelli, F.; Spinelli, E.; Cordero, A.; Covello, D. \& Gorostiaga, J. A. Nerves of the heart: a comprehensive review with a clinical point of view. Neuroanatomy, 8:26-31, 2009.

Mitchell, G. A. The innervation of the heart. Br. Heart J., 15(2):159$71,1953$.

Mizeres, N. J. The cardiac plexus in man. Am. J. Anat., 112:141$51,1972$.

Pather, N.; Partab, P.; Singh, B. \& Satyapal, K. S. The sympathetic contributions to the cardiac plexus. Surg. Radiol. Anat., 25(34):210-5, 2003.

Randall, W. C. \& Armour, J. A. Neural regulation of the heart. New York, Oxford University Press, 1977. pp.13-41. Chapter 2.

Saccomanno, G. The components of the upper thoracic sympathetic nerves. J. Comp. Neurol., 79(3):355-78, 1943.

Standring, S. Gray's anatomy: the anatomical basis of clinical practice. $40^{\text {th }}$ ed. Edinburgh, Churchill Livingstone/Elsevier, 2008.

Corresponding Author:

Professor K.S. Satyapal

Clinical Anatomy

School of Laboratory Medicine and Medical Sciences

College of Health Sciences

University of KwaZulu-Natal

Private Bag X54001

Durban

4000

SOUTH AFRICA

Telephone: + 27312607110 ; +27 837778780

Fax: + 27312607890

Email: satyapalk@ukzn.ac.za

Received: 27-11-2013

Accepted: 06-02-2014 